\title{
"Tem que ter mais conversa entre professor e alunos": a construção da interação em sala de aula via projeto de letramento
}

\author{
"Teacher and students should interact more": the \\ construction of classroom interaction through a literacy \\ project
}

\author{
Juliana Dias dos Santos* \\ Clara Dornelles ${ }^{* *}$
}

\begin{abstract}
RESUMO: O presente trabalho investiga as estruturas de participação da fala-eminteração ocorridas em aulas de Língua Portuguesa, por meio da implementação de um projeto de letramento (KLEIMAN, 2000). Os procedimentos teórico-metodológicos estão embasados na pesquisa-ação (ANDRÉ, 1995) e apoiados na Microetnografia Escolar (ERICKSON, 2001), sob a ótica da Sociolinguística Interacional (GUMPERZ, 1982, 1998, 2001; GOFFMAN, 1964, 1967; RIBEIRO; GARCEZ, 1998). A pesquisa foi desenvolvida em um $8^{\circ}$ ano em Bagé/RS e a análise dos dados ocorreu através dos registros contidos em questionários, notas de campo e gravação e transcrição de vídeos de aulas ocorridas no $1^{0}$ semestre de 2011, durante a realização de estágio curricular. Os estudos sobre os processos interacionais procuram refletir sobre as diferentes participações que ocorrem na sala de aula, portanto, servem como fonte de pesquisa sobre o fazer docente. Como resultado da presente pesquisa, verificou-se que a análise das estruturas de organização da fala-em-interação e as estratégias utilizadas apontaram uma comunicação pedagógica não centrada nas professoras estagiárias, que privilegiaram a construção conjunta do conhecimento e a ampliação do engajamento discursivo dos estudantes.
\end{abstract}

PALAVRAS-CHAVE: Interação. Estruturas de participação. Projeto de letramento.

ABSTRACT: This work investigates the participation structures of interaction in Portuguese classes, during the implementation of a literacy project (KLEIMAN, 2000).

\footnotetext{
* Graduada em Letras Português/Literatura pela Universidade Federal do Pampa (UNIPAMPA) e Professora na Rede Pública Estadual de Ensino de Santa Catarina. E-mail:

julianadias1983@bol.com.br.

** Doutora em Linguística Aplicada pela Universidade Estadual de Campinas (Unicamp) e Professora Adjunta da Universidade Federal do Pampa (UNIPAMPA). Integra o corpo docente do Mestrado Profissional em Ensino de Línguas da UNIPAMPA. E-mail: claraunipampa@gmail.com.
} 
"Tem que ter mais conversa entre professor e alunos": a construção da interação em sala de

aula via projeto de letramento

The theoretical and methodological procedures are based on action research (ANDRÉ, 1995) and supported by School Microethnography (ERICKSON, 2001), through the lenses of Interactional Sociolinguistics (GUMPERZ, 1982, 1998, 2001; GOFFMAN, 1964, 1967; RIBEIRO; GARCEZ, 1998). The research was developed at an 8th grade group of a public school on Bagé/RS and the data analyzed included questionnaries, fieldnotes and video-recordings and transcriptions of classes ocurred on the second semester of 2011, during the development of curricular training period. The studies about interactional processes promote reflection about the different modes of participation that take place in the classroom, and thus, they become a source of research about teaching practices. In our research, we verified that the analysis of participation structures and the strategies used point to a pedagogical communication that are not centred in the teachers, who privileged joint construction of knowledge and the amplification of the discursive engagement of students.

KEYWORDS: Interaction. Participation structures. Literacy project.

\section{Introdução}

O presente artigo problematiza os resultados de um projeto de letramento ${ }^{1}$ elaborado e implementado, durante o estágio curricular no curso de Letras ${ }^{2}$, para promover estruturas de participação (PHILIPS, 1998) que não estivessem centradas na figura do professor (TURA, 1999). Compreendemos a sala de aula como um espaço de construção do sentido no qual a aprendizagem somente se torna possível quando o aluno participa da produção do conhecimento. Assim, nosso estudo está voltado para o processo de coconstrução da interação em uma agência de letramento central em nossa sociedade: a escola.

Partimos da seguinte questão norteadora: como as interações são construídas quando a docente opta por trabalhar com projetos de letramento na comunidade escolar? Assumimos como ponto investigativo a fala-em-

\footnotetext{
${ }^{1} \mathrm{O}$ projeto de letramento intitulado "Trabalhando com gêneros textuais na escola em busca da informação" foi aplicado em um $8^{\circ}$ ano do Ensino Fundamental. Abordou o estudo de diferentes gêneros discursivos, tendo como temática o Patrimônio Histórico, Arquitetônico e Cultural de Bagé, município do interior do Rio Grande do Sul. O referido projeto culminou na confecção de um jornal, em que foram publicadas produções dos alunos, entre elas charges, entrevistas e artigos de opinião.

${ }^{2}$ O Estágio Curricular em Língua Portuguesa foi desenvolvido em dupla, norteado pelo projeto de letramento supracitado, produzido em coautoria com Fernanda Taís Brignol Guimarães e orientado pela Profa. Dra. Fabiana Giovani. A presente pesquisa foi realizada em articulação ao estágio, em procedimentos de pesquisa-ação, como será relatado adiante neste texto.
} 
interação institucional de sala de aula, fundamentado-nos na Sociolinguística Interacional (GUMPERZ, 1982, 1998), a fim de buscar modos alternativos que não reproduzissem as sequências previsíveis Iniciação-Resposta-Avaliação - IRA (GARCEZ, 2006). Dessa forma, nosso objetivo de pesquisa foi descrever e analisar as estruturas de participação co-construídas na interação escolar durante o desenvolvimento de um projeto de letramento (KLEIMAN, 2000).

O projeto buscou unir saberes acadêmicos com o desempenho docente, ressignificando a prática de ensino de leitura e escrita (TINOCO, 2009) e procurando desenvolver no aluno uma visão crítica que fomentasse um papel protagonista na interação estabelecida na esfera escolar. Com a opção pela proposta de letramento como prática social (STREET, 1984) e a tentativa de organização de novas formas de interação, não pretendemos estabelecer um modelo único de atuação docente, mas sim oportunizar aos discentes momentos significativos para engajamento na produção do conhecimento.

$\mathrm{Na}$ sequência, explicitamos a fundamentação teórica que ampara a discussão do tema proposto. Logo após, discutimos a metodologia adotada, apoiada na pesquisa-ação (ANDRÉ, 1995) e na adoção de métodos microetnográficos de pesquisa (ERICKSON; SHULTZ, 1998). Posteriormente, apresentamos a análise e discussão dos dados gerados. Por fim, trazemos as considerações finais, espaço em que foram retomadas as principais experiências adquiridas ao longo desse processo de pesquisa docente.

\section{A sociolinguística interacional e a fala-em-interação}

Esta pesquisa se sustenta na Sociolinguística Interacional (SI), uma tradição de pesquisa desenvolvida a partir de Gumperz (1982, 1998, 2001) e Goffman $(1964,1967)$ e que compreende a fala-em-interação social como lugar de construção de ações, identidades e realidades sociais (RIBEIRO; GARCEZ, 1998). Para Gumperz (2001), a SI surge a partir da necessidade de entender 
"Tem que ter mais conversa entre professor e alunos": a construção da interação em sala de aula via projeto de letramento

como o conhecimento comunicativo que vai além da gramática e do léxico afeta o processo de interação. Nas palavras do próprio autor:

Ao invés de considerar os processos interpretativos como algo prédefinido, a SI sugere (1) quais são as interpretações mais prováveis, (2) quais são as asserções e processos inferenciais pelos quais essas interpretações são alcançadas e (3) como elas se relacionam com o que é dito literalmente ${ }^{3}$ (GUMPERZ, 2001, p. 223).

É importante também retomar a reflexão de Goffman (1964) sobre a "situação negligenciada", uma vez que justifica o nosso olhar para o aqui-eagora da interação como lugar de construção da realidade social que possui sua própria normatividade. Em Goffman (1967), o autor expande a problematização dos rituais próprios da interação. A base de seu pensamento indica que as interações são altamente ritualísticas e que os atores sociais se valem (nem sempre conscientemente) de conhecimentos dos procedimentos rituais para preencher ou não as expectativas dos outros interagentes e, assim, produzir desfechos mais condizentes com suas próprias expectativas. No entanto, esse jogo da interação situada é coordenado, e a ação de um interagente influencia a do outro no próprio momento em que é construída, o que mostra que os atores sociais não estão sujeitos a forças superestruturais, mas sim agindo estrategicamente nas situações específicas.

A partir de Garcez (2006, p. 66), a fala-em-interação social é compreendida como uma "noção que inclui as atividades vocais e não-vocais constituintes da interação social humana e que engloba todas as formas faladas de uso da linguagem em interação social, institucionais ou não, em co-presença ou não". A fala-em-interação social constitui o objeto da pesquisa em SI; o locus em que se encontra o agenciamento humano e as forças estruturantes das instituições que, em última análise, como dissemos, constituem-se situadamente. Mas a interação não acontece assim de modo genérico. Em uma mesma situação social podemos desempenhar diferentes papéis e acionar diferentes enquadres, que, na visão de Goffman (1974, p. 10), referem-se à

\footnotetext{
${ }^{3}$ Nossa tradução de: "Instead of taking interpretive processes for granted, IS analysis suggests (1) what the most likely interpretations are, (2) what the assumptions and inferential processes are by which they are achieved, and (3) how they relate to "what is literally said".
} 
definição da situação (o que está acontecendo) conforme o ponto de vista dos seus participantes e dos princípios que estruturam os eventos interacionais.

\section{Interação na sala de aula}

Quando falamos em aprendizagem escolar estamos nos referindo à formulação de questões pelo professor, sujeito que vai construir o conhecimento com o educando, através da interação professor-aluno dentro de uma estrutura de participação. O conceito de estrutura de participação foi originalmente desenvolvido por Susan Philips, observando os modos de organização da interação verbal.

No contexto escolar, essa estrutura, geralmente, está formulada nos padrões da iniciação-resposta-avaliação (IRA). A sequência IRA é recorrente nas escolas por apresentar um caminho rápido de inserção de novas informações aos alunos. Segundo Garcez (2006, p. 68), essa sequência é canônica no fala-em-interação de sala de aula convencional em quase todo o mundo. O autor acrescenta que raramente "se observa uma aula sem ocorrências da sequência, havendo mesmo salas de aula nas quais a interlocução entre alunos e professores se dá predominantemente por encadeamento de sequências desse tipo". Sinclair e Coulthard (1975 apud GARCEZ, 2006) apresenta a sequência IRA como:
1. Professor: Iniciação
Marta: que horas são?
2. Aluno: Resposta
Lucas: duas e meia.
3. Professor: Avaliação
Marta: muito bem.

Essa sequência triádica é constituída por uma pergunta inicial (cuja resposta na maior parte das vezes é conhecida por quem pergunta) seguida por uma resposta dada pelo aluno. A resposta obtida é avaliada pelo professor, podendo ser positiva ou negativa, conforme sua expectativa. Garcez (2006) relata que o referido procedimento, embora comum na sala de aula 
"Tem que ter mais conversa entre professor e alunos": a construção da interação em sala de aula via projeto de letramento

convencional, é pouco utilizado na interação cotidiana. O autor ainda afirma que

[...] na sala de aula, não apenas essas perguntas ocorrem e recorrem, como também deixam de ser objeto de protesto. Em outras palavras, os participantes concordam que o que estão fazendo juntos se faz mediante uma organização interacional tal que se outorga a um certo participante, tipicamente aquele identificável como "professor", o direito de fazer perguntas insinceras, mais propriamente chamadas de perguntas de informação conhecida, perguntas-teste, perguntas para demonstração, ou outros termos que apontam para o caráter institucional do que se está fazendo naquilo que reconhecemos como sendo fala-em-interação de sala de aula (GARCEZ, 2006, p. 69).

Ressaltamos que a interação faz parte do processo de construção de conhecimento. Mesmo quando o aluno é somente ouvinte, ou o professor faz perguntas "insinceras", o aluno participa da interação que estabelece a troca de saberes entre professor-aluno. No entanto, percebemos que é possível proporcionar novas formas de participação, diferentes das práticas geralmente adotadas em sala de aula, em que o professor adquire o papel de falante (aquele que está inteiramente envolvido com a fala e sua recepção) e o aluno de ouvinte (sujeito envolvido com o que está sendo dito), assumindo o turno conversacional apenas quando solicitado. Nas palavras de Cajal (2001), na esfera escolar, encontramos a regra básica da conversação ${ }^{4}$, falar um de cada vez, muitas vezes imposta pela cultura tradicional ${ }^{5}$ da escola:

[...] falar um de cada vez, apresenta certa universalidade, [...] e, na interação de sala de aula, é exigida pelo professor. Este, por comandar o sistema de comunicação da sala, tem o direito de escolher 0 aluno que deverá tomar 0 turno seguinte. 0 falante que está com a palavra escolher o falante seguinte é a primeira forma de alocação de turnos apresentada por Sacks, Schegloff e Jefferson

\footnotetext{
4 Trazemos o exemplo da conversação, pois Cajal (2001) menciona que uma interação é produzida socialmente e apresenta certa universalidade, válida para a maioria das situações.

5 Nas palavras de Tura (1999, p. 95), "a cultura escolar pode ser bem evidenciada na organização do espaço físico da escola, no tipo dos móveis, nas diferentes disposições do ambiente e na forma de sua edificação; assim como nos padrões de relacionamento social, expectativas de comportamento e normas de organização". Importante ainda lembrar que, para Goffman (1998, p. 14), as regras culturais "estabelecem como os indivíduos devem se conduzir em virtude de estarem em um agrupamento e estas regras de convivência, quando seguidas, organizam socialmente o comportamento daqueles presentas à situação".
} 
(1974, p.7). A segunda, um falante se auto-selecionar para obter 0 turno, geralmente acontece quando o falante atual pára sem interpelar ninguém ou quando a situação está imersa em silêncio. Sua ocorrência se dá com maior freqüência em conversações espontâneas, em contexto informais (CAJAL, 2001, p. 131).

Para a interação em sala de aula ser bem sucedida, os interagentes necessitam aprender continuamente, ou seja, precisam reformular, corrigir, estender e aprofundar as informações adquiridas. Desta forma, presenciamos na sala de aula diferentes tipos de participações que ocasionam a construção de conhecimentos significativos.

Sobre este assunto, Gumperz (1998) relata que os participantes negociam interpretações no momento da interação e que, quando a fase introdutória estabelecida entre as relações interpessoais é negociada, pode surgir a cooperação do falante, estabelecendo um ritmo longínquo de turnos conversacionais. Esse evento comunicacional por si só (re)constrói o conhecimento dos membros enquanto interagentes que constitui a interação.

Por meio da interação, o professor pode motivar a fala do aluno, pois sua opinião é significativa no ambiente escolar, local em que ideias e conceitos são trocados através da interação de diferentes sujeitos para a construção do conhecimento coletivo. Cajal diz que:

\begin{abstract}
A vida de sala de aula, como a de qualquer outra situação social, não é dada a priori, nem tomada de empréstimo a outra situação, ao contrário, é construída, "definida e redefinida" a todo momento, revelando e estabelecendo os contornos de uma interação em construção. Interação enquanto "encontro" em que os participantes, por estarem na presença imediata uns dos outros, sofrem influência recíproca, daí negociarem ações e construírem significados dia a dia, momento a momento (CAJAL, 2001, p. 127).
\end{abstract}

Retomando as palavras da autora, a conversa de sala de aula enquanto interação em construção permite ao professor aprender com os alunos, analisar o que os alunos sabem, o que eles querem em termos educacionais e o que pretendem nas relações sociais mediadas pelo professor. 
Desta forma, a fala-em-interação estabelecida entre professor-aluno ocorre de maneira menos autoritária. Assim, embora não haja dúvida de que é o professor quem conduz a discussão, a interação em sala de aula ocorre com a finalidade de formar seres humanos capazes de "compreender a cidadania", conforme os Parâmetros Curriculares Nacionais de Língua Portuguesa (PCN LP), sujeitos capazes de "posicionarem-se de maneira crítica, responsável e construtiva nas diferentes situações sociais, utilizando o diálogo como forma de mediar conflitos e de tomar decisões coletivas ${ }^{6 \prime \prime}$ (BRASIL, 1997, p. 7).

\section{A metodologia de ensino via projetos de letramento}

Nos últimos anos, temos presenciado uma tentativa de mudança acerca do ensino de Língua Portuguesa, visando à inserção de práticas inovadoras no contexto educacional. Percebemos também que alunos e professores estão notando a importância da ressignificação do ensino de língua nas escolas brasileiras, desestabilizando as práticas pedagógicas ditas tradicionais (CUNHA, 2010).

A elaboração de um projeto articulado aos estudos do letramento possibilita novas experiências e implica planejamentos conjuntos entre professor/alunos, proporcionando aos participantes uma visão ampla das aulas de Língua Portuguesa (TINOCO, 2008). Nas palavras de Kleiman, um projeto de letramento se constitui como

[...] um conjunto de atividades que se origina de um interesse real na vida dos alunos e cuja realização envolve o uso da escrita, isto é, a leitura de textos que, de fato, circulam na sociedade e a produção de textos, que serão lidos, em um trabalho coletivo de alunos e professor, cada um segundo sua capacidade [...] (KLEIMAN, 2000, p. 238).

Segundo Oliveira (2010, p. 131), trabalhar na perspectiva de letramento "significa reconfigurar o modo de participar em sala de aula, criando novas

\footnotetext{
${ }^{6}$ Esses são objetivos gerais do ensino fundamental.
} 
imagens (cenas) do ato de ensinar/aprender a língua". Nessa metodologia de ensino, a sala de aula funciona como espaço cultural, em que professores, alunos e demais agentes de letramento ${ }^{7}$ se (re)conhecem e se articulam no processo de ensino-aprendizagem, por meio de uma perspectiva da linguagem como prática social. O letramento, a partir desta visão de linguagem, é concebido, a partir de Street (1984, p. 1), como "práticas e concepções sociais de leitura e escrita".

De acordo com Kleiman (2002, p. 23), "o processo de ensino da língua materna e de introdução e inserção do aluno nas práticas sociais de uso da escrita sustenta-se na oralidade letrada do professor alfabetizador". Ou seja, a verbalização do professor é vista como o elemento principal nos contextos de ensino-aprendizagem. Dessa forma, precisamos (re)pensar no papel do professor enquanto formador de novos leitores e usuários da língua escrita, exercendo a função de agente social.

Conforme Kleiman, também acreditamos que "é na escola, agência de letramento por excelência de nossa sociedade, que devem ser criados espaços para experimentar formas de participação nas sociedades letradas" (KLEIMAN, 2007 , p. 4). A prática do letramento implica uma postura interacionista do professor que, ao conceber a língua como lugar de interação de sujeitos, deverá focalizar o desenvolvimento de competências e habilidades linguísticas para a participação em sociedade, promovendo o letramento em sala de aula.

Para romper com a rigidez da cultura escolar tradicional e estabelecer relações interdisciplinares, os projetos de letramento podem ser uma ótima estratégia de "lançar para frente" um processo de socialização entre professor, aluno e demais sujeitos da comunidade, todos engajados em um trabalho coletivo (KLEIMAN, 2007; OLIVEIRA, 2010). Esse esforço por promover o engajamento do aluno é explicitamente mencionado nos Parâmetros

\footnotetext{
${ }^{7} \mathrm{O}$ agente de letramento é capaz de articular interesses partilhados pelos aprendizes, organizar um grupo ou comunidade para a ação coletiva, auxiliar na tomada de decisões sobre determinados cursos de ação, interagir com outros agentes (outros professores, coordenadores, pais e mães da escola) de forma estratégica e modificar e transformar seus planos de ação segundo as necessidades em construção do grupo (KLEIMAN, 2007, p. 21).
} 
Curriculares Nacionais de Língua Estrangeira (PCN LE), segundo o qual o engajamento discursivo do aprendiz refere-se à "sua capacidade de se engajar e engajar outros no discurso de modo a poder agir no mundo social" (BRASIL, 1998, p. 15).

Seguindo a metodologia de projetos de letramento, a relação estabelecida entre educador e educando passará a ser de colaboração, com interação na busca da construção do conhecimento em tomadas de decisão coletivas, como apontamos, em referência anterior aos PCN LP. Em nossa compreensão, o engajamento discursivo pode ser proporcionado quando buscamos incentivar os alunos a produzirem conhecimento envolvendo-se em diferentes práticas sociais (não apenas escolares) por meio de estruturas de participação que provoquem modificações e desafiem a estabilidade do padrão IRA na sala de aula.

\section{Metodologia da pesquisa}

Este estudo trata-se de uma pesquisa-ação, sustentado no campo de investigação da SI, conforme explicado anteriormente, e segue princípios da microetnografia (ERICKSON, 2001; ERICKSON; SHULTZ, 1998). Vincula-se à pesquisa-ação, pois consiste na busca de mudança de uma situação específica no contexto de ensino: possibilitar maior participação dos alunos na aula de Língua Portuguesa. Configura-se como uma pesquisa qualitativa, pois se preocupa em interpretar determinada realidade social, leva em consideração o ambiente natural como fonte de dados, a descrição desses elementos e o significado que as pessoas observadas dão à situação vivenciada (ANDRÉ, 1995).

Quanto à microetnografia, segundo Erickson (2001), trata-se de um meio de desvendar a natureza interacional nos espaços de aprendizagem num nível de análise que nos permite sugerir meios de mudar para melhor as práticas pedagógicas, a partir de seu registro e descrição pormenorizada. São realizados registros em vídeo, colocando-se uma ou duas filmadoras na sala de aula para 
registro integral das atividades. Posteriormente, as filmagens são assistidas por completo, marcando-se os momentos que mais chamaram a atenção para análise detalhada, como explicaremos adiante. Como nesta pesquisa integramos microetnografia e pesquisa-ação, os vídeos foram visualizados após cada aula, para que assim pudéssemos pensar nos encaminhamentos pedagógicos posteriores, visando a participação alargada dos alunos na construção do conhecimento.

O primeiro passo da pesquisa foi a negociação com a direção da escola e com a professora de português para a realização do estágio, que consistiu em observações, atividade diagnóstica e práticas pedagógicas. Após observarmos duas aulas ministradas pela professora regente, aplicamos um questionário para investigar o ambiente escolar em que os alunos estavam inseridos e lançamos a seguinte pergunta: O que você acha das aulas de Português? A resposta obtida de uma das alunas foi: "São boas, mas tem que ter mais conversa entre 0 professor e os alunos" ${ }^{\prime \prime}$. Logo após a aula, todos os questionários foram lidos, no entanto, esse em especial chamou a atenção. Inquietas com essa resposta, desenvolvemos um projeto de letramento intitulado "Trabalhando com gêneros textuais na escola: em busca da informação". Conforme sugere a pesquisa-ação, com esse projeto buscamos produzir compreensão (pesquisa) e mudanças (ação) das/nas interações ocorridas na sala de aula. A metodologia dos projetos de letramento foi escolhida como metodologia de ensino por promover o engajamento dos alunos em práticas letradas para além da esfera escolar.

O projeto desenvolvido com a turma apresentou como tema o patrimônio histórico, arquitetônico e cultural de Bagé. A cidade estava completando duzentos anos e seus moradores estavam bastante envolvidos com diferentes ações de comemoração dessa data. A partir da temática, desenvolvemos um trabalho sistemático, articulando o estudo dos gêneros da esfera jornalística (charge, artigo de opinião, entrevista, reportagem) aos demais conteúdos

\footnotetext{
${ }^{8}$ Fragmento do diário de campo escrito durante o Estágio III. Bagé, 2011.
} 
indicados pela professora regente. A intenção deste trabalho consistiu na elaboração de um pequeno jornal, que circulou localmente, divulgando o trabalho elaborado pelos educandos.

O passo seguinte foi a geração dos dados, realizada de maio a junho de 2011. Por se tratar de pesquisa de cunho microetnográfico, explicamos que seria necessária a filmagem das aulas e produção de um diário reflexivo sobre a prática de ensino. Assim sendo, solicitamos aos responsáveis pelos alunos, a permissão para os registros audiovisuais, contidas em um Termo de Consentimento.

Para análise dos dados, focamos as filmagens ${ }^{9}$, que totalizaram cerca de 20 horas, com o objetivo de investigar as estruturas de participação ocorridas na interação dos envolvidos na comunidade escolar. Para tanto, seguimos as orientações de Erickson e Shultz (1998), que sugerem ao pesquisador que siga as seguintes etapas: (I) assistir ao vídeo por inteiro com poucas interrupções, assinalar as principais ocasiões apontadas na gravação; (II) fazer um levantamento das partes mais importantes ${ }^{10}$ que devem ser observadas detalhadamente; (III) identificar as estruturas de participação; (IV) transcrever ${ }^{11}$ a fala e gestos dos participantes, sempre que necessário; e (V) testar a validade do modelo de interação, comparando as ocorrências semelhantes presentes no corpus da pesquisa.

A seguir, apresentamos a análise e discussão de dados em que procuramos investigar as possíveis formas de participação em um ambiente escolar, tendo como principais atores os sujeitos participantes da fala-eminteração, envolvidos em um processo de aprendizagem advindo de um projeto de letramento. A análise segue a sequência cronológica e apresenta dados representativos de estruturas de participação presentes nas interações registradas nas aulas de Língua Portuguesa. Serão expostos excertos de nota

\footnotetext{
${ }^{9}$ Em filmadora digital situada sobre um tripé.

${ }^{10}$ Consideramos como parte importante as diferentes formas de estrutura de participação da fala-em-interação de sala de aula, objeto desta pesquisa.

${ }^{11}$ Os dados gerados foram analisados detalhadamente e transcritos conforme as convenções de Jefferson (LODER, 2008). Os sinais utilizados nas transcrições constam no anexo.
} 
"Tem que ter mais conversa entre professor e alunos": a construção da interação em sala de aula via projeto de letramento

de campo e segmentos de fala-em-interação construída nos padrões IniciaçãoResposta-Avaliação, como também, sequências distintas dos padrões IRA com a finalidade de mostrar como a participação foi estabelecida a partir da elaboração de um projeto de letramento.

\section{A sequência IRA no projeto de letramento}

A seguir, apresentamos transcrições de uma filmagem (Excerto 01) de prática social ocorrida durante o desenvolvimento do projeto de letramento. Como explicamos na metodologia, para a concretização do projeto de ensino, idealizamos a elaboração de um jornal acerca do patrimônio histórico, arquitetônico e cultural de Bagé. Para tanto, envolvemos os alunos em situações de aprendizagem, dentre as quais podemos citar: a visitação à redação de um jornal, o passeio turístico pela cidade, a roda de conversa com uma repórter e a entrevista com uma arquiteta. A realização do passeio serviu como ponte de acesso às informações relativas aos casarões e principais pontos turísticos da cidade. Posteriormente, os alunos realizaram uma pesquisa detalhada sobre os prédios e publicaram o resultado no jornal da turma.

Nessa ocasião, contamos com a presença de uma guia turística, Júlia ${ }^{12}$, que assumiu a função de falante principal. Dessa forma, as docentes adotaram o papel de ouvinte, estando na mesma posição ocupada por seus alunos, como ilustra o excerto abaixo:

${ }^{12}$ Adotaremos pseudônimos para preservar a identidade dos participantes, garantindo-lhes anonimato, conforme explicitado nos termos de consentimento. 
Excerto $01(20 / 05 / 2011)$

01 Júlia: pessoal aqui nós estamos em frente a (.) que praça é

$02 \quad$ essa aqui

03 Alunos: praça dos desportos

04 Janaína: Rio Branco

05 Alunos: [praça dos desportos]

06 Janaína: [Rio Branco]

07 Janaína: Rio Branco

08 Júlia: o nome dela é, como é que tu falou

$09 \quad$ ((dirige o olhar para Janaína))

10 Janaína: Rio Branco

11 Júlia: o nome dessa praça é Rio Branco ((confirma com a cabeça))

12 Caroline: eu não sabia

13 Júlia: e vocês sabem o que que foi aqui antigamente (1.6)

14 ninguém chuta

15 Alunos: hã

16 Júlia: que que foi aqui na praça esportes antes de ser (.)

17 bem antes de ser praça, anos atrás

18 Alunos: fo::i

19 Márcio: bah ele disse campo de futebol aqui atrás ele disse

20 campo de futebol

21 Júlia: ninguém [chuta]

22 Eduarda: [casas] casas

23 Alunos: fo::i

24 Júlia: vocês imaginem que isso aqui era tudo campo (.) o que

$25 \quad$ poderia ter aqui

26 Caroline: Cemitério

27 Júlia: mu::ito bem

28 Eduarda: Cemitério (.) ai que horror::

Ao analisarmos este excerto, percebemos que Júlia introduz a sua fala de maneira informativa e, repentinamente, faz uma pequena pausa, retomando a palavra em forma de pergunta (linha 1 e 2). Desta forma, Júlia estabelece uma abertura para que os alunos tomem o turno de fala (linhas 3 a 7).

A partir das perguntas, Júlia foi alinhando a turma em um mesmo foco de atenção e conduziu os estudantes para a interação. Alguns alunos se autoselecionaram para os turnos de fala e responderam as perguntas elaboradas por ela (linhas 4 a 7, 12, 18, 22, 26). Porém, Júlia ignorou as respostas "erradas" (linhas 3 e 19), repetindo apenas a resposta desejada (linha 10). 
"Tem que ter mais conversa entre professor e alunos": a construção da interação em sala de aula via projeto de letramento

Um aspecto relevante a se observar nesse caso diz respeito ao encadeamento das perguntas elaboradas. Júlia faz a iniciação na linha 1 , pergunta que praça é essa aqui. Duas respostas são obtidas nos seguimentos contínuos: Praças de esportes (linhas 3 e 5) e Rio Branco (linhas 4, 6, e 7). Júlia, na linha 8, ratifica a aluna Janaína através do seu olhar, isto é, remete a sua atenção visual àquela a quem pretende passar o papel de falante, e pede para repetir sua resposta, a aluna responde. Mantendo o piso conversacional, ou seja, os interagentes estavam engajados no mesmo foco de atenção, Júlia retoma a fala da aluna ratificada, balançando a cabeça em sinal de concordância.

Nota-se ainda que na sequência (linha 16), Júlia lança outra pergunta, faz uma pausa acentuada, esperando uma resposta, porém não a obtém. Logo após, retoma seu turno (ninguém chuta), de modo que, abre espaço para que os alunos apresentem suposições. Os discentes respondem (linhas 19, 22), no entanto, nenhuma resposta se faz satisfatória. Na sequência (linhas 24 e 25), Júlia dá uma pista ("vocês imaginem que isso aqui era tudo campo (.) o que poderia ter aqui") e uma das alunas "acerta". Fica evidente na fala de Júlia (linha 27) a avaliação acerca da interação.

Trata-se aqui de uma fala-em-interação movida por perguntas, edificada a partir de hipóteses, que, por fim, culminou na tríade IRA. Para Garcez (2006, p. 69),

[...] se é verdade que a seqüência IRA é um método altamente eficaz e econômico de apresentar informação nova aos alunos e/ou de verificar em que medida eles dispõem de certas informações e assim por diante, também é verdade que se trata de um modo eficaz e econômico de reproduzir conhecimento, não exigindo necessariamente um engajamento dos participantes que produzem os turnos em segunda posição na efetiva construção do conhecimento em pauta, ao menos não no sentido de torná-lo seu. Basta lembrar das vezes em que nos encontramos na situação, como alunos ou como professores, em que inúmeras respostas em segunda posição são necessárias até se chegar "onde o professor quer", o que por vezes acaba se assemelhando a uma sessão de adivinhação ou leitura da mente do professor. 
Coube à Júlia, nesse tipo convencional de interação escolar, o direito de avaliar a resposta do aluno. No entanto, percebemos que a interação nos padrões da IRA aqui observada proporcionou muito mais do que a avaliação propriamente dita. Permitiu também que a guia estimulasse o engajamento dos educandos.

É importante ressaltar que as estruturas de participação sofrem alterações de acordo com processos interacionais à medida que os participantes as modificam por meio de ações conjuntas. Na sala de aula, de acordo com a cultura escolar, o professor é quem organiza o encontro social, conforme Schulz:

\footnotetext{
Em cada atividade que ele propõe, novos direitos à participação e à fala podem ser construídos e modificados (CAZDEN, 2001; PHILIPS, 2001; JONES \&THORNBORROW, 2004). Não se pode perder de vista o manejo local feito pelos participantes nas formas de organizar sua participação. Assim, as estruturas de participação, o acesso e a obtenção dos turnos de fala e o piso conversacional não podem ser vistos como estruturas determinadas ou estanques: eles são coconstruídos nas interações [...] e estão contextualizados em atividades maiores com as quais os participantes estão envolvidos. (SCHULZ, 2007, p. 75-76).
}

A aprendizagem se dá na prática social e é instituída por meio da interação. Segundo Garcez (2006), a partir da sua estrutura, a organização da fala-em-interação pode ter funções que variam entre o controle social, a reprodução de conhecimento e a construção conjunta de conhecimento. A tríade IRA acima apresentada, retrata uma aula que foi além dos muros da escola. Neste cenário, nos deparamos com uma sequência de perguntas, carregadas de informações importantes para o grupo de alunos em questão. A avaliação feita pela guia não deve ser vista como algo negativo, pois o propósito de levar informações novas aos discentes foi alcançado, no momento em que os discentes passaram a aprender um pouco mais sobre a história de Bagé/RS. Ainda que o conhecimento produzido tenha sido do tipo "enciclopédico" e possa ser caracterizado como reprodução do conhecimento, a sequência possibilitou o engajamento dos alunos na interação. 
"Tem que ter mais conversa entre professor e alunos": a construção da interação em sala de aula via projeto de letramento

No excerto apresentado, percebemos que a estrutura de participação está encadeada na sequência IRA, mas possibilita uma interação rápida e simples, porém, não menos importante, em termos de engajamento, se compararmos com as estruturas apresentadas a seguir.

\section{Interação em sala de aula fora dos padrões IRA}

Nesta ocasião, contamos com a presença de uma jornalista do Jornal Zero Hora, Rafaela, pois partimos do princípio de que as aulas seriam mais significativas se aproximássemos os discentes do contexto de produção de um jornal. Para execução da atividade, prevista no projeto de letramento, organizamos uma roda de conversa com o objetivo de proporcionar aos educandos o contato com um profissional da esfera jornalística. Neste momento de interação, Rafaela traz informações referentes ao lead ${ }^{13}$ do Jornal.

\section{Excerto $02(25 / 05 / 2011)$}

01 Rafaela: ah essa essa essa (.)quase uma sigla que tem ali

02

03

04

05

06

07

08

09

10

11

12

13

14

15

16

17

18 embaixo (.) 3QOCP isso aqui são perguntas básicas que vocês tem que responder no lead, lead é aquela primeira- primeiro parágrafo de uma: reportagem a gente chama de lead aquele parágrafo tem que chamar o leitor para a leitura tem que prender o leitor na matéria ele tem que ser bom se ele for bom o leitor vai ler aquilo ali vai se interessar, perai perai saber mais o que está escrito na matéria, se aquilo ali for ruim ninguém mais vai ler a matéria de vocês. hã: vocês conhecem a zero hora (0.5) vou usar como exemplo a zero hora (1.2) o lead da zero hora é em negrito cada jornal adota uma: prática não é uma regra também (.) as regras elas existem para que a gente possa quebrá-las mas não é uma regra que se faça um lead em negrito a zero hora costuma fazer ele em negrito justamente para chamar atenção para essa entrada da matéria (.) e aquilo que tem aqui $3 \mathrm{QOCP}$

${ }^{13}$ Lead se refere à abertura (início) de uma notícia, ou seja, o primeiro parágrafo. No texto jornalístico, o primeiro parágrafo tem que responder às perguntas básicas: quem fez, o quê, quando, onde, como e por quê. 
19

20

21

22

23

24

25

26

27

28

29

30

31

32

33

34

35

36

37

38

39

40

41

42

43

44

45

46

47 Letícia:

48

49

50

51

52

53

54

55

56

57

58

59

60

61

62 eu não descrevi para vocês deixei em sigla para vocês hã: puxarem pela memória depois para lembrar o que que é são perguntas básicas que a gente pode responder (.) precisa responder no lead na entrada (.)três questões o que, quem, quando, então o que que é que está acontecendo hã o que vocês estão tratando quem é que está envolvido quem são os personagens envolvidos nessa história e quando (.) quando isso aconteceu quando o fato aconteceu quando o acontecimento do cotidiano quando aconteceu que quem e quando depois OCP onde (.) onde que essa história que estamos narrando aconteceu como que ela aconteceu de que maneira isso tudo aconteceu e por quê, então são seis perguntas básicas que se vocês responderem no lead hã praticamente vocês estão conseguindo fazer com que o leitor fique ali e continue lendo porque no resto do texto vocês vão desenvolver melhor essas questões vocês não vão contar uma história enorme para cada uma dessas perguntas na entrada da matéria na entrada da matéria são respostas simples e curtas o que tá acontecendo quando aconteceu o que aconteceu é onde como e quem são os personagens envolvidos e depois no resto do texto vocês vão detalhar vão vão informar um pouco melhor colocar o leitor mais por dentro da informação que você querem levar (1.1) (x) está legal assim (.) está bem (.) vocês estão entendendo (.) estou falando grego (.) estão quietos

eles são bem quietos uma das coisas que ã nós estamos observando é que várias pessoas estão passando por aqui: e eles não estão questionando (.) gente é uma oportunidade ímpar de vocês aprenderem agora (.) tá a professora regente para nos acompanhar e dar qualquer apoio ã eu e a Amanda ${ }^{14}$ também estamos aqui (.) então são várias pessoas envolvidas nesse processo de aprendizagem de vocês então assim a Rafaela está aqui perguntem explorem porque ela sabe muito mais sobre esse gênero a reportagem do que qualquer uma de nós três (.) então perguntem para a Rafaela ela sabe responder e qualquer coisas que nós não soubermos também a gente pesquisa e traz pra vocês depois (.) explorem aproveitem a pessoa da Rafaela todo o conhecimento que ela tem ela está disposta a:: passar um pouquinho para vocês (.)

${ }^{14}$ Pseudônimo adotado pela colega de estágio 
63 Rafaela: o jornalista ele é uma pessoa muito curiosa

64 jornalista é muito curioso e eu achei muito

65 interessante é: a gente sabe que isso acontece mas é

66 muito bacana a gente ir: para uma sala de aula e se

67 deparar com uma situação de inclusão e ver que

68 funciona isso hoje no nosso sistema de educação (2.3)

69 a curiosidade do jornalista já fez a jornalista ficar

70 olhando ai e achar:: muito bacana muito interessante

Na situação acima, é relevante observar que Rafaela introduziu sua fala através da exposição, sem que houvesse resposta propriamente dita por parte dos alunos. Nas interações em aula, o silêncio dos alunos é significativo. Segundo Laplane (2000, p. 64).

O silêncio pode ter valores positivos, indicando maior entendimento ou intimidade; ele pode não ser apenas uma ausência de palavras, mas uma presença ativa e realizar a necessidade defensiva de evitação.

Essas ocorrências muitas vezes assinalam a resistência ou a dificuldade em emitir alguma consideração a respeito do assunto que se está tratando. No exemplo acima, Rafaela solicita a participação em dois momentos (linhas 11, 44 a 46), o que provoca a reação da professora (linha 47).

No decorrer desse excerto, é possível observar que a Letícia ${ }^{15}$ buscou construir um diálogo com seus alunos, de maneira a demonstrar que a participação deles é importante na construção do conhecimento. A intervenção da estagiária possibilitou também um esclarecimento e uma justificativa sobre o comportamento dos seus alunos. Percebendo a pausa de Letícia, Rafaela retoma o turno conversacional, relatando a sua experiência, enquanto jornalista. A novidade em relação à sequência IRA está na explicitação da docente a respeito da importância de os discentes participarem tomando o turno para de fato expandir o conhecimento com alguém que não é a professora e sobre informações que provêm do campo de atuação profissional

\footnotetext{
${ }^{15}$ Pseudônimo adotado pela estagiária pesquisadora.
} 
"Tem que ter mais conversa entre professor e alunos": a construção da interação em sala de aula via projeto de letramento

da expositora. Contudo, isso não é suficiente para promover a tomada de turno por parte dos alunos, nem engajamento relevante para produzir conhecimento.

O próximo segmento analisado também pode ser considerado diferente do que acontece nas aulas tradicionais. O excerto trata de uma aula, na qual, recebemos uma arquiteta, Mônica, para falar sobre o patrimônio histórico de Bagé. Na segunda metade desta aula, realizamos uma entrevista, para a qual os discentes elaboraram perguntas, colocando em prática os ensinamentos obtidos na aula anterior com o auxílio da jornalista. A preparação prévia de perguntas foi uma estratégia para promover maior engajamento da turma, já que o gênero entrevista cria a demanda de tomada de turno.

Excerto $03(27 / 05 / 11)$

01 Letícia: então começa Bru:no

02 Bruno: o que é patrimônio

03 Letícia: fala alto

04 Mônica: patrimônio, patrimônio são coisas (0.5) patrimônio

05

06 pode ser material e pode ser imaterial, os prédios é

patrimônio material por exemplo um coral uma

07 orquestra são patrimônio imaterial, patrimônio é o

08 que deve ser preservado para preservar a cultura de

09 uma cidade

10 Letícia: número 2

11 Janaína: sou eu

12 Letícia: pode falar então

13 Janaína: o que caracteriza um patrimônio histórico

14 Mônica: patrimônio histó:rico da arquitetura que nem eu falei hoje é hã tem (interesse por) objetos prédios que tem

17 valores a serem preservados ou uma pessoa morou lá ou

18 foi um arquiteto importante né: isso caracteriza o patrimônio histórico ele é histórico porque conta uma

19 história onde onde esse pré:dio:: foi construído

20 morou alguém ou a arquitetura é importante

21 Letícia: número [trê-]

22 Júnior: [o que] significa tombar um prédio

23 Mônica: tombar o prédio é um instrumen:to hã legal né que 24 previne o prédio de: de alterações, que: que segure

25 (.) então se tu olhar a prefeitura velha a do trem

26 ela é tombada nela se for feita alguma correção ela

27 tem que ir para a avaliação do patrimônio histórico 
"Tem que ter mais conversa entre professor e alunos": a construção da interação em sala de aula via projeto de letramento

28

29

30

31

\section{2}

\section{Mariana: prédio tombado}

33 Letícia: fala de novo Mariana por favor

34 Mariana: prédio tombado

35 Letícia: não. lê a tua pergunta

36 Mariana: cite cite alguns prédios tombados

37 Mônica: aqui em Bagé a Catedral é tombada nacionalmente, o

42

43 Letícia:

44 Mônica:

45 Letícia:

Dom Dio:go a nível estadual a prefeitura velha ah o centro administrativo o IMBA o palacete Pedro Osório $\mathrm{o}$ : coreto e todos esses prédios foram tombados agora: no último governo, (.) foram todos esses prédios tombados

46 Mônica: é que tem uma por exemplo importância nacional que

é a catedral ela foi nacionalmente tombada

48 Letícia: é porque no site do IPHAN eu achei a catedral e onde

49

50 era ali aquela região do::: como é que é o nome do do

forte da santa tecla

51 Mônica: ah é o forte de santa tecla, ah é o forte de santa

52

53

54

55

56

57

58 Letícia: tecla se tu olhar não tem nada, era, era o local do forte mas é uma zona que é tombada que foi feito um projeto lions (eu espero) né para se mostrar para os alunos e para população geral que ali foi um sítio importante, sitio é lugar $(x)$ importante historicamente (.) e por isso tombado

59 Luciana: quando você passou a se interessar pela arquitetura 60 e por quê

61 Mônica: ah olha(x)eu acho que desde pequena eu olhava para

62

63

64

65

66

67

68 Letícia: esses prédios e me encantava o Aleijadinho que é um artista que fazia igreja e, também o Niemeyer que é o arquiteto que fez Brasília que é um arquiteto moderno então foi nesse momento que eu: eu me interessei pela arquitetura (.) não só a arquitetura que deve ser preservada tombada como a arquitetura moderna Cássia))

69 Mateus: tu gosta da história dos prédios de Bagé ((interpretado por

70 Mônica: oi? Cássia))

71 Mateus: tu gosta da história dos prédios de Bagé ((interpretado por 
72 Mônica: ah eu acho que a gen:te é privilegiado aqui em Bagé

73

por ter essa história vinculada à arquitetura (3.1)

74

acho que é um luga::r importante (3.7)(x) das únicas

75 três ou quatro cidades gaúchas tem essa história para

76 contar

$77 \quad(4.0)$

78 Letícia: pergunta número sete está com quem

79 Fabiane: eu

80 Fabiane: a arquitetura histórica de Bagé influencia na

81 elaboração de novos projetos

82 Mônica: (x)(Mônica não entende a pergunta formulada)

83 Letícia: essa arquitetura histórica influencia nos novos 84 projetos

85 Mônica: cla:ro a gente hã até na faculdade a gente sabe que a

86 arquitetura não sai do nada, a criação da

87 arquitetura, ela sempre se volta na referência do

88 passado né se faz projeto, olhando para a catedral

89 por exemplo eu posso fazer uma boate (.) então esses

90 prédios são registros da arquitetura de como era

91 feito antes e hoje a gente pesquisa antes de fazer um

92 projeto e pode eventualmente utilizar hã as técnicas

93 geométricas a tipologia como a gente fala que é a

94 estrutura geométrica do projeto

$\mathrm{Na}$ primeira e terceira linhas, encontramos o gerenciamento da participação. Letícia ordena o início das perguntas e assim que Carlos conclui sua fala, Letícia ordena que ele aumente o tom de voz (fala alto). A seguir, Mônica toma o turno e responde ao questionamento do aluno. Letícia torna a orientar a fala dos alunos (linhas 10, 21, 32, 56 e 68), ordenando os turnos de fala. É interessante notar que durante a terceira pergunta (linha 21), Letícia é interrompida ao gerenciar a fala de Bruno, pois, conforme percebemos, ele já havia entendido a estrutura da participação. Assim sendo, Letícia não gerencia a pergunta seguinte. No entanto, Mariana se atrapalha ao formular a pergunta (linhas 32 e 34) e mais uma vez Letícia organiza a atividade, orientando a aluna a ler a pergunta conforme estava em seu caderno (linha 35). Após a resposta de Mônica, Letícia se auto-seleciona e faz uma pergunta, buscando maiores esclarecimentos. Mônica direciona o olhar para Letícia e, posteriormente, se dirige aos demais interagentes, ratificando a participação de todos. 
"Tem que ter mais conversa entre professor e alunos": a construção da interação em sala de aula via projeto de letramento

Na sequência, o aluno Mateus introduz uma pergunta (interpretado por Cássia), e construímos assim um espaço no qual todos os alunos tiveram oportunidade de interagir, atravessando as barreiras da exclusão escolar. Concluindo sua fala, Mônica faz uma pausa e Letícia retoma o gerenciamento (linha 78). Logo após, Fabiane assume o turno, porém não consegue formular sua pergunta, ao ponto que Mônica responde de forma inadequada e inintelegível (linha 82). Assim sendo, Letícia reelabora a pergunta de Fabiane, que por sua vez obtém uma resposta adequada.

O que presenciamos nessa sequência de fala-em-interação de sala de aula é o gerenciamento da participação dos alunos por Letícia. A estagiária da turma prepara a atividade proposta, coordenando o andamento da interação, mas acima de tudo oportuniza momentos de falas organizadas, dando voz aos educandos, que por sua vez participam de um processo de ensinoaprendizagem.

O excerto de transcrição a seguir mostra um momento incomum na sala de aula. Para incentivar o engajamento discursivo dos alunos para a expressão de pontos de vista e assim desenvolver capacidades de argumentação necessárias para a produção de artigos de opinião para o jornal da escola, optamos por desenvolver um debate sobre um tema polêmico e bastante presente em seu cotidiano: o uso do celular em sala de aula. Para contextualizar a atividade, trazemos um fragmento do diário de campo:

\footnotetext{
Chegando o momento de trabalharmos o gênero artigo de opinião. Lembrei de uma aula ministrada na UNIPAMPA por nossa orientadora do estágio. Conversei com a Amanda e concordamos que o tribunal do júri era uma maneira eficiente de darmos início ao poder de argumentação dos alunos. Também concordamos que era necessário variar o tema, pois falar apenas de Bagé, já estava se tornando cansativo.

Lançamos um debate sobre o uso do celular na escola, dividimos a turma em dois grupos. O primeiro deveria defender a proibição do celular no ambiente escolar, o outro deveria apresentar argumentos favoráveis ao uso do aparelho telefônico. A professora regente, sempre presente, foi convidada a exercer o papel de jurada. (Diário de campo, 01/06/11).
}

Excerto $04(01 / 06 / 2011)$ 
01 Letícia: bom na escola (.) é proibido ou não é proibido o uso 02 do celular

03 Mariana: é

04 Amanda: aqui na escola é proibi:do

05 Amanda: não [a gente só pode usar na ho:ra do recreio

06 Helena: [é proibido sim não é para usar, na hora do

07 recreio tu saiu da sala de aula

08 Letícia: então assim não é para falar só pensem celulares

09 devem ser proibidos em sala de aula=

10 Guilherme: =não

11 Letícia: (psiu) só pensa em toda a escola mesmo no intervalo

12 (.)eles podem atrapalhar as aulas podem também ser

13 uma ferramenta útil (.) tá então vamos pensar e agora

14 vamos fazer o seguinte o grupo da esquerda vai se

15 reunir e vai defender o uso no celular da escola tá o

16 grupo da esquerda vai ser contra o uso do celular

17 Viviane: ah::

18 Letícia: não gente depois a gente troca

19 Amanda: não quer dizer que realmente vocês sejam contra mas

20 vocês vão ter que fazer o papel-

21 Letícia: faz de conta que esse grupo é o dos alunos e eles vão

22 ter que apresentar argumentos para a professora

$23 \quad$ Helena do porque eles devem usar o celular e o daqui

24 vão ter que apresentar argumentos como se eles fossem

25 parte dos professores e dos pais dizendo porque não

26 usar o celular na escola

27 Amanda: vocês têm que tentar ser o mais convincente possível

28 tá porque depois a professora vai julgar qual grupo

29 argumentou melhor

30 Letícia: podem sair das classes a gente vai dar uns minutinhos 31 para vocês conversarem a respeito disso.

No início deste excerto 4, percebemos Letícia lançando um tema polêmico: o uso do celular na escola. Percebemos também que na fala de Letícia existe uma convocação implícita para que os alunos participem do turno seguinte (linhas 1 e 2). Mariana se auto-seleciona e responde (sim), Amanda retoma a pergunta e especifica ainda mais, (linha 4). Mariana assume novamente o turno, respondendo a indagação de Amanda (linha 5). Nesse momento, percebemos que a fala de Mariana é questionada pela professora regente, que por sua vez sobrepõe a fala de Mariana (linhas 6 e 7). 
Neste momento, Letícia expande o assunto, dando assim a oportunidade de reflexão sobre o tema em discussão. Nas linhas 13 a 16 temos um período de instrução da atividade feito por Letícia. Ao terminar as instruções, Viviane se mostra contrariada com a escolha dos grupos (linha 17). Letícia toma a palavra novamente e explica que posteriormente os grupos inverterão os papéis. Amanda entra na conversa e esclarece (linha 19 e 20), Letícia concorda com a ideia e interrompe o turno de fala de Amanda, assumindo o turno mais uma vez. Amanda, por sua vez, espera Letícia concluir sua fala e volta a explicar a atividade (Linha 27). Logo após, Letícia disponibiliza um tempo para que os alunos conversem sobre a atividade proposta.

\section{Excerto $05(01 / 06 / 2011)$}

01 Letícia: gente assim oh um de cada vez um fala depois o outro 02 toma a palavra tá para não ficarem gritando

03 Guilherme: começa eles aqui professora

04 Amanda: olha só quando um grupo estiver com a palavra tiver 05 falando o outro não interrompe tá deixa o grupo

06 argumentar depois o outro vai argumentar

07 Letícia: então vamos lá começa aqui defendem porque usar o 08 celular na sala de aula podem falar falem alto

09 Mariana a gente achou melhor que o celular fosse usado na

10 sala de aula para falar assim (.) para falar com o

11 pessoal de fora

12 Eduarda: [com os familiares]

13 Caroline: [pode acontecer alguma coisa urgente]

14 Letícia: e o porquê disso

15 Amanda: ah porque o celular é importante

16 Letícia: tá e assim vocês tem que falar o porquê se vocês

17 acham que o celular não atrapalha porque não

18 atrapalha a aula

19 Bruno: [ué deixa no silencioso

20 Mariana: [não atrapalha deixa no silencioso e desligado não

21 tem como atrapalhar

22 Letícia: o que tu ia falar

23 Bruno: deixa no silencioso ninguém vai ver pede para sair 24 fala e depois volta

25 Letícia: tu alguém mais posso passar a palavra para o outro 26 grupo

27 Amanda: pode 
28 Letícia: vocês o que vocês acham [que]

29 Mateus: [aqui] porque não pode usar o

30 telefone na sala de aula ((interpretado por Cássia)

31 Letícia: é

32 Mateus: eu acho que não pode usar por causa das colas na

33 provas tipo se um familiar que falar com vocês tem 0

34 telefone na escola não precisa falar no telefone de

35 vocês ((interpretado por Cássia)

36 Bruno: e se não tem telefone na escola

37 Alunos: mas tem

38 Luciana: tem dois

39 Letícia: quem mais do grupo quer falar não vou passar para lá 40 então fala

41 Bruno: e se não tiver outro telefone no colégio

42 Alunos: mas tem

43 Alunos: ((todos falando ao mesmo tempo))

44 Mariana: mas é melhor falar do meu celular

45 Eduarda: pede para sair e fala

46 Luciana: mas não pode

47 Guilherme: mas não pode sair

48 Letícia: a professora que vai julgar quem usou os argumentos

49 melhor não está entendendo é só grito vamos lá quem é

50 que estava com palavra o grupo daqui segue falando

51 Eduarda: mas os pais nem sempre tem o telefone da escola

52 Luciana: ué e porque vocês não dão ((aplausos risos))

53 Alunos: ( ) ((alunos falando ao mesmo tempo))

54 Eduarda: [e se for uma urgência]

55 Mariana: [e se for uma urgência] e o telefone da escola tiver

$56 \quad$ ocupado

57 Eduarda: se for uma urgência vão ligar para o nosso celular

58 que é mais rápido

59 Alunos: ( ) ((alunos falando ao mesmo tempo))

60 Letícia: Mateus o que tu acha

61 Mateus: que é importante para falar com a família

62 quando precisa ligar ((interpretado por Cássia))

63 Letícia: tá e assim óh para que mais o telefone serve

64 Luciana: para jogar Cássia))

65 Mateus: só para colar e roubar de dentro da aula ((interpretado por

66 Luciana: para incomodar para tirar a atenção dos alunos e para

67 colar em matemática

68 Alunos: ( )((alunos falando ao mesmo tempo))

69 Mariana: o celular é importante para várias coisas não é só

70 pra colar e ligar

71 Mateus: tá é importante fora do colégio ((interpretado por Cássia))

72 Mariana: fora do colégio e dentro do colégio também 
73 Alunos: não

74 Mateus: óh telefone serve de calculadora pode mandar mensagem

75 se está no silencioso tu vai lá na rua, fala com a

76 pessoa fácil e pega a resposta no telefone e deu ((interpretado

por Cássia))

77 Luciana: tá só me diz uma coisa se fosse importante isso é

78 certo se fosse importante as professoras iam chegar e

79 falar assim ó gente agora todo mundo vai pegar o seu

80 celular e vai fazer tal coisa porque não fazem

81 Alunos: toma (ehehehe).hh:::::

82 Luciana: se fosse importante como um livro a professora ia

83 dizer é obrigado trazer todos os dias o telefone para

84 dentro da sala de aula

Letícia e Amanda, respectivamente, retomam as orientações, combinando com os participantes como deve funcionar a atividade (linha 1 e 4 a 6) depois o outro vai argumentar (linhas 1 a 2 e 4 a 6 ). Na linha três, Vinicius fala, no momento a estagiária não ratifica a fala de Vinicius, mas atende o seu pedido na linha 07.

Ao iniciar sua fala, Mariana (linha 9) apresenta argumentos não muito convincentes. Dessa forma, Letícia reforça que os argumentos necessitam ser mais persuasivos. À medida que os argumentos foram ficando mais fortes, os turnos dos alunos se sobrepuseram (linhas 59 e 68). A partir da linha 74, encontramos falas bem argumentadas. Logo, a professora regente concordou com o grupo que defendia a proibição do uso do celular na escola, pois conforme as palavras da docente, "a escolha do grupo aconteceu porque os seus argumentos foram convencendo no decorrer do debate".

Os alunos aprovaram a atividade, engajando-se de forma bastante entusiasmada. No momento seguinte, invertemos os papéis e trocamos os grupos de posição. 0 interessante foi que o mesmo grupo ganhou, dessa vez argumentando a favor da utilização do celular. Por conseguinte, ficou evidente aos alunos que o poder da argumentação modifica o pensamento das pessoas. A professora falou sua opinião sobre o assunto, e complementou que os argumentos foram bem utilizados, promovendo uma reflexão sobre a utilização do celular na sala de aula. 
"Tem que ter mais conversa entre professor e alunos": a construção da interação em sala de aula via projeto de letramento

Ao analisarmos esse segmento, percebemos a existência de dois enquadres distintos: a aula e o debate. Primeiramente, percebemos cenas de sala de aula em que Letícia e Amanda assumiram o papel canônico de professoras, produzindo comandos para a condução do fluxo de interação. Quando o enquadre de debate prevaleceu, as estagiárias adotaram uma postura motivadora/mediadora da discussão. Esse debate serviu de exercício modelar para aprender a se posicionar diante de polêmicas. Nas aulas seguintes, seriam focalizados temas do projeto de letramento não tão familiares aos alunos e sobre os quais deveriam se posicionar em artigos de opinião para o jornal da turma.

Figura 1 - Artigo de opinião e charge no jornal produzido

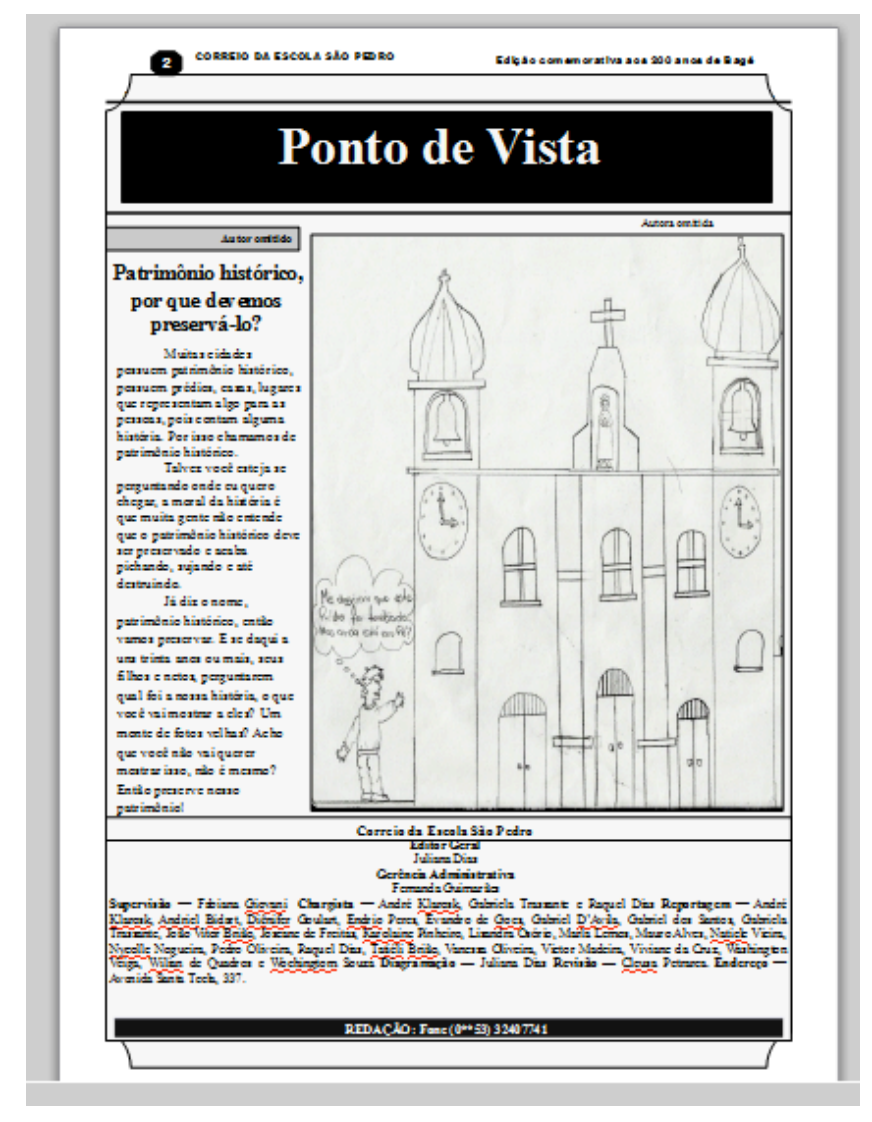

Fonte: Arquivo Pessoal

É importante enfatizar que quando há variação na estrutura de participação é possível verificar a existência de diferentes alinhamentos por 
parte de todos os participantes: embora o professor tenha um papel importante no gerenciamento dos turnos, ele não é o único a tomar a palavra e nem sabe aonde ela vai chegar. Conforme os estudantes se apropriam das práticas, definem como exercer as tarefas e como negociar seus direitos de participação, eles se engajam e se tornam participantes autênticos do seu aprendizado. Logo, percebemos uma modificação no modo de aprender e na forma de ensinar (SCHULZ, 2007).

\section{Considerações finais}

No contexto investigado, as interações estabelecidas entre os participantes da fala-em-interação instituíram novas práticas pedagógicas, tendo como foco principal o conhecimento dos alunos. A imagem que observamos nesse ambiente interacional foi a de um espaço em que a construção do conhecimento foi viabilizada por meio do desenvolvimento de um projeto de letramento que possibilitou novas configurações da fala-eminteração que, por sua vez, somente foram possíveis em função de novos modos de organização da participação em sala de aula. A partir dos dados levantados, percebemos que a interação estabelecida na sequência IRA não foi o núcleo das aulas de Língua Portuguesa, pois outras formas de participação foram se concretizando. Dentre elas, podemos elencar a conversa ministrada pela repórter, em que observamos os alunos assumindo o papel de ouvinte; a entrevista realizada com uma arquiteta, na qual, presenciamos os discentes assumindo o papel de repórteres e as professoras, de mediadoras e por fim, 0 debate, em que os alunos participaram ativamente do processo de construção do conhecimento, colaborando na construção de enquadres atípicos em seu contexto escolar.

No decorrer desta pesquisa, concluímos que é possível organizar a aula para que os discentes se tornem participantes autênticos do seu aprendizado, sendo co-construtores do processo de ensino-aprendizagem. Embora esse tipo de intenção esteja presente em muitos trabalhos sobre a prática docente, nem 
"Tem que ter mais conversa entre professor e alunos": a construção da interação em sala de aula via projeto de letramento

sempre são trazidos dados empíricos que evidenciem como propiciar esses momentos de construção conjunta de conhecimento, tal como apresentamos em nossos dados e discussão.

Esperamos que nosso estudo possa contribuir para pensar o desafio que se coloca aos docentes de línguas (e não apenas de língua portuguesa): como desenvolver propostas na perspectiva de favorecer a formação de sujeitos que percebam criticamente o valor da linguagem e seu uso em sociedade? Associar ensino e pesquisa na elaboração de projetos que visem envolver/engajar os alunos em práticas sociais, a partir da reflexão docente sobre os modos de organizar a aula e sobre os modelos de interação culturalmente estabelecidos (e que precisam ser reforçados ou modificados), é um caminho importante nessa direção.

\section{Referências}

ANDRÉ, Marli Eliza D. A abordagem qualitativa da pesquisa. In: . Etnografia da prática escolar. Campinas: Papirus, 1995. p. 13-22.

BRASIL. Ministério da Educação. Secretaria de Educação Fundamental. Parâmetros curriculares nacionais: língua portuguesa. Brasília, 1997.

BRASIL. Ministério da Educação Secretaria de Educação Fundamental. Parâmetros curriculares nacionais: língua estrangeira. Brasília, 1998.

CAJAL, Irene Baleroni. A interação de sala de aula: como o professor reage às falas iniciadas pelos alunos? In: COX, Maria Inês Pagliarini; ASSIS-PETERSON, Ana Antônia (Org.). Cenas de sala de aula. Campinas: Mercado de Letras, 2001. p. 125-159.

CUNHA, Rosana. O jornal escolar sob a ótica do ensino de gênero e da formação continuada do professor. In: VOVIO, Claúdia; SITO, Luanda; GRANDE, Paula (Org.). Letramentos: rupturas, deslocamentos e repercussões de pesquisas em linguística aplicada. Campinas: Mercado das Letras, 2010. p. 141-161.

ERICKSON, Frederick. Prefácio. In: ASSIS-PETERSON, Ana Antônia; COX, Maria Inês Pagliari (Org.). Cenas de sala de aula. Mercado das Letras: Campinas, 2001. p. 9-17.

ERICKSON, Frederick; SHULTZ, Jeffrey. O quando de um contexto: questões e métodos na análise da competência social. In: RIBEIRO, Branca Telles; GARCEZ, Pedro M. (Org.). Sociolinguística interacional: antropologia, linguística e sociologia em análise do discurso. Porto Alegre: Age, 1998. p. 142-153. 
"Tem que ter mais conversa entre professor e alunos": a construção da interação em sala de aula via projeto de letramento

GARCEZ, Pedro. A organização da fala-em-interação na sala de aula; controle social, reprodução do conhecimento, construção conjunta de conhecimento. Calidoscópio, São Leopoldo, v. 4, n. 1, p. 66-80, jan./abr. 2006.

GOFFMAN, Erving. A situação negligenciada. In: RIBEIRO, B. T. e GARCEZ P. M. (orgs.). Sociolinguística interacional: antropologia, lingüística e sociologia em análise do discurso. Porto Alegre: AGE EDITORA, 1998. p. 11-15.

GOFFMAN, Erving. Frame analysis: an essay on the organization of experience. New York: Harper \& Row, 1974.

GOFFMAN, Erving. The neglected situation. American Anthropologist, Washington, v. 66, n. 2, p. 133-136, Dec. 1964.

GOFFMAN, Erving. Interaction ritual: a study of face-to-face interaction. Chicago: Aldine, 1967.

GUMPERZ, J. Interactional sociolinguistics: a personal perspective. In: SCHIFFRIN, Deborah; TANNEN, Deborah; HAMILTON, Heidi. Handbook of discourse analysis. Malden: Blackwell, 2001. p. 215-228.

GUMPERZ, John J. Convenções de contextualização. In: RIBEIRO, Branca Telles; GARCEZ, Pedro M. (Org.). Sociolinguística interacional: antropologia, lingüística e sociologia em análise do discurso. Porto Alegre: Age, 1998. p. 16-30.

GUMPERZ, John. Discourse strategies. Cambridge: Cambridge University Press, 1982.

KLEIMAN, Angela B. Letramento e suas implicações para o ensino de língua materna. Revista Signo, Santa Cruz do Sul, v. 32, n. 53, 2007.

KLEIMAN, Angela B. O processo de aculturação pela escrita: ensino de forma ou aprendizagem da função? In. KLEIMAN, Angela B.; SIGNORINI, Inês. $O$ ensino e a formação do professor: alfabetização de jovens e adultos. Porto Alegre: Artemed, 2000. p. 223-243.

KLEIMAN, Angela B. Oralidade letrada e competência comunicativa: implicações para a construção da escrita em sala de aula. Scripta, Belo Horizonte, v. 6, n. 11, p. 23-38, 2002.

LAPLANE, Adriana Lia Friszman. Interação e o silêncio na sala de aula. Caderno Cedes, São Paulo, ano 20, n. 50, p. 55-69, abr. 2000.

LODER, Letícia L. O modelo Jefferson de transcrição: convenções e debates. In. LODER, Letícia L.; JUNG, Neiva M. (Org.). Fala-em-interação social: introdução à análise da conversa etnometodológica. São Paulo: Mercado das Letras, 2008. p. 126161.

OLIVEIRA, Maria do Socorro. Variação cultural e ensino/aprendizagem de língua materna: os projetos de letramento em comunidade de aprendizagem. In: VOVIO, Claúdia; SITO, Luanda; GRANDE, Paula (Org.). Letramentos: rupturas, deslocamentos 
"Tem que ter mais conversa entre professor e alunos": a construção da interação em sala de aula via projeto de letramento

e repercussões de pesquisas em Linguística Aplicada. Campinas: Mercado das Letras, 2010. p. $141-161$.

PHILIPS, Susan U. Algumas fontes de variabilidade cultural na ordenação da fala. In: RIBEIRO, Branca Telles; GARCEZ, Pedro M. (Org.). Sociolinguística interacional: antropologia, lingüística e sociologia em análise do discurso. Porto Alegre: Age, 1998, p. 16-30.

RIBEIRO, Branca Telles; GARCEZ, Pedro M. (Org.). Sociolinguística interacional: antropologia, linguística e sociologia em análise do discurso. Porto Alegre: Age, 1998.

SCHULZ, Lia. A construção da participação na fala-em-interação de sala de aula: um estudo microetnográfico sobre a participação em uma escola municipal de Porto Alegre. 2007. 163 f. Dissertação (Mestrado em Linguística Aplicada) - Universidade Federal do Rio Grande do Sul, Porto Alegre, 2007.

STREET, Brian. Literacy in theory and practice. Cambridge: Cambridge Universtity Press, 1984.

TINOCO, Glícia M. Azevedo de M. Projetos de letramento: ação e formação de professores de língua materna. 2008. 240 f. Tese (Doutorado em Linguística Aplicada)Instituto de Estudos da Linguagem, Universidade Estadual de Campinas, Campinas, 2008.

TINOCO, Glícia M. Azevedo de M. Usos sociais da escrita + projetos de letramento = ressifignificação do ensino de língua portuguesa. In: GONÇALVES, Adair Vieira; BAZARIM, Milene (Org.). Interação, gêneros e letramento: a (re)escrita em foco. São Paulo: Claraluz, 2009. p. $151-174$.

TURA, Maria de Lourdes. Escola, homogeneidade e diversidade cultural. In: GONÇALVES, Maria Alice Rezende (Org.). Educação e cultura: pensando em cidadania. Rio de Janeiro: Quartet, 1999. p. 87-111. 


\section{ANEXO}

\section{SINAIS UTILIZADOS NA TRANSCRIÇÃO ${ }^{16}$}

\section{Aspectos de produção da fala}

- (ponto final) - elocução produzida com entonação descendente

? (ponto de interrogação) - elocução produzida com entonação ascendente. Não sinaliza necessariamente uma pergunta

, (vírgula) - sinaliza elocução produzida com entonação de "continuação", intermediária entre as entonações ascendente e descendente : (dois-pontos) - som ou sílaba prolongado. Usamos tantos dois-pontos quanto necessários para sugerir a duração do prolongamento

(flecha para cima) - som mais agudo do que os do entorno

- $\quad$ (hífen) - corte abrupto na produção vocal

fala (sublinha) - ênfase no som

FAla (maiúscula) - som em volume mais alto do que os do entorno

${ }^{\circ}$ fala $^{\circ}$ (sinais de graus) - som em volume mais baixo do que os do entorno

fala (sinais maior do que e menor do que) - fala acelerada

[ ] (colchetes) - fala sobreposta (mais de um interlocutor falando ao mesmo tempo)

\section{Inspirações/expirações/risos}

hh (série de $\mathbf{h}$ ) - expiração ou riso

\section{Lapsos de tempos}

$(2,4)$ (número entre parênteses) - medida de silêncio (em décimo de segundos)

(.) (ponto entre parênteses) - silêncio de menos de 2 décimos de segundo

\footnotetext{
${ }^{16}$ Os sinais utilizados na transcrição das falas baseiam-se em: LODER, Letícia Ludwig. O modelo Jefferson de transcrição: convenções e debates. In: LODER, Letícia L., JUNG, Neiva Maria. (Org.). Fala-em-interação social: introdução à análise da conversa etnometodológica. Campinas: Mercado das Letras, 2008.
} 
"Tem que ter mais conversa entre professor e alunos": a construção da interação em sala de aula via projeto de letramento

Formatação, comentários, dúvidas

$=\quad$ (sinais de igual) - elocução contínguas

( ) (parênteses vazios) - segmento de fala que não pôde ser transcrito

(fala) (segmento de fala entre parênteses) - transcrição duvidosa

((levanta da cadeira)) (parênteses duplos) - descrição de atividade nãovocal 